\title{
Japan reaches for the stars
}

Radio-dish looks set

\section{to excel}

Japan is now poised to take a world lead in millimetre-wave radioastronomy - the study of molecular clouds and starformation regions - thanks to a farsighted decision by the Japanese Ministry of Education more than a decade ago to support the plans of Tokyo Observatory.

For while American molecular astronomers smart under the effective abandonment of their own country's plans for a large (25-metre) dish to operate in this wavelength range (see Nature 12 August, p.596), Professor Kenji Akabane of the Tokyo Obervatory will announce this week at the International Astronomical Union meeting at Patras, Greece, his first observations with a 45-metre dish and a $5 \times 10$-metre-dish interferometer - a combination which is likely to outclass the millimetre-wave equipment of other nations for a number of years.

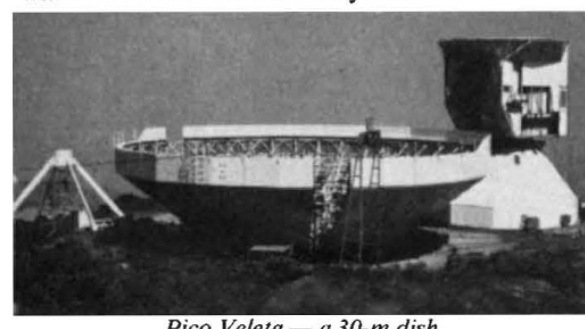

Pico Veleta - a 30-m dish

This telescope complex, which took 13 years to construct and cost $£ 20$ million, is now in operation at Nobeyama, $200 \mathrm{~km}$ north of Tokyo.

There is only one doubt about the telescopes - that they are sited in Japan. There they are limited by a relatively humid atmosphere, which absorbs low wavelengths. Thus, said a British millimetrewave radioastronomer this week, Japan may be restricted to measurements at wavelengths not much shorter than $1 \mathrm{~cm}$, which in molecular terms means a limitation to the observations of relatively rare long molecules. Studies of isotopic abundances in the Universe - an important project for millimetre-wave astronomy - need shorter wavelengths. The Tokyo observatory, however, reckons that Nobeyama will reach down to $2 \mathrm{~mm}$.

If the Nobeyama telescope fails to reach down that far there is a chance that it will be suspassed within a few years by other millimetre-wave telescopes, planned or under construction.

France, Germany, and Spain will be next, with the $£ 15$-million Institut de Radioastronomie Millimetrique (IRAM). IRAM has an administrative headquarters in Grenoble and two telescope sites: one in southern Spain, on Pico Veleta near
Granada, and one in the southern French Alps at the Plateau de Bure.

Pico Veleta is to have a 30 -metre dish, whose steel-work is nearly complete - but the telescope is unlikely to be taking data before early 1984 . According to Dr Dennis Downes, one of the IRAM team, this telescope should reach down to $1-\mathrm{mm}$ wavelengths. But doubts have been expressed about that objective: the IRAM ielescopes are to be open to the air and Sun, and so they will be distorted by wind and differential solar heating.

The exact shape of the dish must be maintained to within a wavelength of the radiation being studied - in other words 1 $\mathrm{mm}$. To achieve this, the steelwork of the Pico Veleta telescope is to be heated to a uniform temperature; and the Plateau de Bure 15-metre dishes (of which there will be three making a $\mathrm{T}$-shaped interferometer) will be stiffened with carbon fibre, cost

\section{Remote sensing for all at UN}

\section{Vienna}

Remote sensing capabilities are emerging as a keynote of Unispace-82, the Second United Nations Conference on the Peaceful Exploration and Utilization of Outer Space, now taking place in Vienna. Virtually every national delegation expressed its committment to, and hopes for, remote sensing, and although some delegates privately expressed the views that remote sensing was still a solution in search of a problem, such sentiments were kept strictly outside of the official proceedings.

Remote sensing, for example, is to be the mainstay of the United States "global habitability" programme which is expected, during the $1980 \mathrm{~s}$, to develop into an umbrella for the research scheduled for the US space platform. "Global habitability" is intended to open up the entire land mass of the Earth to human habitation.

Yet the use of such techniques to survey another country contains the seeds of international tension. One of the problems to which remote sensing is repeatedly urged as a solution is the more rational use of land resources. But such techniques inevitably cut across traditional concepts of national and even personal privacy. The Soviet Union is a strong supporter of new international legislation to outlaw the improper use of data gained by satellite. As Dr Andrei P. Kapitsa, director of the Soviet stand at the exhibition associated with Unispace- 82 pointed out, the publication in the Western press of predicted shortfalls in the Soviet harvest (based on satellite data) immediately raised world wheat prices, causing an extra drain on Soviet hard currency reserves.

Significantly, one of the most fervent pleas for the establishment of international principles on the use of satellite data came allowing. Whether these untried methods will achieve the necessary accuracy is yet to be seen. Moreover the interferometer, will take some time to construct.

Besides IRAM, Britain, together with The Netherlands, plan to build a £7-million, 15-metre dish in Hawaii. These plans require environmental approval by the Hawaii State legislature, expected towards the end of this year. The BritishDutch dish, protected by a dome transparent to the radiation, should reach down almost to the edge of the millimetrewave atmospheric "window" at $0.35 \mathrm{~mm}$. But observations are not expected there before 1986 .

Thus Japan is likely to enjoy a substantial lead in this branch of astronomy, possibly the first basic science in which it might take a world lead, at least until 1984

Robert Walgate and Alun Anderson

from Brazil, a country frequently quoted as a classic case where only remote sensing can provide adequate survey facilities. President Joao Baptista de Oliveira Figueiredo spoke of remote sensing as an "instrument both valuable and dangerous" since it "impinges on the sovereignty of states over their natural resources".

The problem becomes even more complex with marine resources. One of the greatest advantages which Cuba derived from participation in the manned "Interkosmos" programme, according the Cuban cosmonaut Arnaldo Tamayo Mendez, was the discovery of new fishing grounds. However, although one of the purposes of Unispace-82 was to show third world countries what space techniques are available, and although the European Space Agency has recently offered African states experimental facilities aboard Spacelab some 25 per cent of the nations represented in the United Nations have not yet reached a level of development where participation of any kind in a remote sensing survey is an economic possibility. The use of satellites to determine fishshoals in international waters could mean that those shoals fail to reach the traditional fishing grounds of the disadvantaged nations.

To obviate such inequities, some speakers at the forum of nongovernmental organizations (NGOs), which took place in parallel to the main sessions, urged that the third world should strive for its own launch capability, but without clearly suggesting how this might be achieved. More practical would be the creation of an international pool of landresource data as part of the United Nations committment to space. The two space superpowers already have a data-pooling 